\title{
Depression and maintenance of smoking cessation after myocardial infarction with focus on education
}

\author{
Kathrine Hald ${ }^{1}$, Jakob Rasmussen ${ }^{2}$, Helene Kirkegaard ${ }^{3}$, Claus V. Nielsen ${ }^{1}$, Lucette K. Meillier ${ }^{4}$, Mogens L. Larsen ${ }^{* 5}$ \\ ${ }^{1}$ Department of Public Health, Section of Clinical Social Medicine and Rehabilitation, Aarhus University, Aarhus, Denmark \\ ${ }^{2}$ BeneFiT, Viborg, Denmark \\ ${ }^{3}$ Department of Public Health, Section of Epidemiology, Aarhus University, Aarhus, Denmark \\ ${ }^{4}$ DEFACTUM, Concern Quality, Central Denmark Region, Aarhus, Denmark \\ ${ }^{5}$ Danish Centre for Inequality in Health, Department of Cardiology, University Hospital Aalborg, Denmark
}

Received: June 22, 2016

DOI: $10.5430 /$ cns.v4n3p86
Accepted: June 26, $2016 \quad$ Online Published: June 30, 2016

URL: http://dx.doi.org/10.5430/cns.v4n3p86

\begin{abstract}
Objective: The aim of the study was to investigate the association between depression and maintenance of smoking cessation at 1-year follow-up in patients admitted with first-incidence acute myocardial infarction (MI) with a focus on educational level. Methods: From the $1^{\text {st }}$ of September 2002 to the $31^{\text {st }}$ of December 2004, 388 patients $<75$ years old were admitted at Aarhus University Hospital in Denmark with first-incidence MI. The patients were screened for depression 6 weeks after admission and offered cardiac rehabilitation (CR). Patients were included if they stopped smoking at admission or in the next 6 weeks, if they were screened for depression and if they gave information concerning smoking status.

Results: A quarter of the patients were screened positive for depression. There was no significant difference in the participation at the smoking cessation part of the rehabilitation for patients screened positive or negative for depression, whether the results were adjusted for gender and educational level $(\mathrm{OR}=0.84 ; p$-value $=.75)$ or not $(\mathrm{OR}=0.75 ; p$-value $=.56)$. There was a significant association between a positive depression screening and failing to maintain a smoking cessation in men $(\mathrm{OR}=7.67$; $p$-value $=.03)$ at 1 -year follow-up. When adjusted for educational level a significant association was still seen $(\mathrm{OR}=7.48$; $p$-value $=.01$ ).

Conclusions: There was a significant association between a positive depression screening and failing to maintain a smoking cessation in men at 1-year follow-up. The result was consistent after adjusting for educational level.
\end{abstract}

Key Words: Cardiovascular disease, Myocardial infarction, Cardiac rehabilitation, Depression, Smoking cessation, Socioeconomic status

\section{INTRODUCTION}

Cardiovascular disease is a chronic disease in which patients may experience functional limitations and reduced quality of life..$^{[1,2]}$ It is possible to reduce functional limitations and increase quality of life through participation in cardiac rehabilitation $(\mathrm{CR}) \cdot{ }^{[1,2]} \mathrm{CR}$ reduces modifiable risk factors, cardiovascular morbidity and mortality. ${ }^{[3-5]}$ To optimize the effect of CR it is recommended, that CR is planned as a longterm course, which among other includes patient education and behavioural interventions. ${ }^{[4,6,7]}$

One of the most important areas that CR should focus on is

\footnotetext{
*Correspondence: Mogens L. Larsen; Email: lytken.larsen@rn.dk; Address: Danish Centre for Inequality in Health, Department of Cardiology, University Hospital Aalborg, Hobrovej 18-22, Building 613, 9000 Aalborg, Denmark.
} 
the importance of smoking cessation. ${ }^{[8]}$ Smoking is a major risk factor for cardiovascular disease, it is estimated, that persistent smokers have a higher risk of recurrent coronary events (hazard ratio 1.51) compared to non-smokers and quitters. ${ }^{[9]}$ Similarly do smokers have a higher risk of cardiovascular death compared to non-smokers and quitters. ${ }^{[10]}$

Patients with depression are at higher risk for recurrent coronary events and cardiovascular death. ${ }^{[11]}$ One reason, among others, is that depressed patients are more likely to decline participating in CR, and if participating, their chances to apply the acquired knowledge in relation to life style changes, including smoking cessation, are lower than in patients without depression. ${ }^{[12]}$ A systematic review and meta-analysis have stated that depressed patients have a lower confidence in completing CR, a lower sense of coherence and lower social support. ${ }^{[13]}$ The prevalence of depression in the Danish population is estimated to $2 \%-4 \% .{ }^{[14]}$ Compared to this, it has been estimated that the prevalence of depression in patients diagnosed with myocardial infarction (MI) is approximately 20\%. ${ }^{[15]}$ Furthermore a study found that MI-patients almost had a threefold likelihood of being diagnosed with posttraumatic stress disorder, which was also found to be associated with depression. ${ }^{[16]}$

Socioeconomic status, such as educational level, influences on the patient participation in CR. ${ }^{[17,18]}$ Also, the propensity to make lifestyle changes such as smoking cessation increases with the educational level of the patients. ${ }^{[19,20]} \mathrm{A}$ study found that men with hypertension, who had a lower educational level, to a lesser extent reported to have obtained smoking cessation. ${ }^{[21]}$

It has not been possible to find studies that examine the relationship between depression and maintenance of smoking cessation, nor with a focus on educational level. On this background, we wanted to examine the association between depression and maintenance of smoking cessation with a focus on educational level.

\section{Objective}

The aim of the study was to investigate the association between depression and maintenance of smoking cessation at a 1-year follow-up in patients admitted with first-incidence acute MI with a focus on educational level.

\section{MethodS}

From the $1^{\text {st }}$ of September 2002 to the $31^{\text {st }}$ of December 2004, 388 patients $<75$ years old were admitted at Aarhus University Hospital in Denmark with newly diagnosed firstincidence MI. Of these, 333 were offered to participate in a socially differentiated CR-project. The criteria for referral to

Published by Sciedu Press the differentiated CR were based on age, educational level and marital status. Details concerning the socially differentiated CR-project have previously been published. ${ }^{[22]}$ All patients who participated were at least offered CR similar to what is recommended by the Danish National Board of Health and the Danish Society of Cardiology at the current time. ${ }^{[23]}$

All patients were screened for depression six weeks after admission. If the screening indicated depression, patients were advised to consult their general practitioner (GP) for diagnosis and eventually treatment. The depression-screeninginstrument CMD-SQ, which has a high validity, was used. ${ }^{[24]}$ QMD-SQ combines six sub scales and has three components: A one page questionnaire, a template to decode the score and a one page guide to register the sum score. SCL-8, which is a sub category of QMD-SQ, is used in relation to the sub scale "mental disorders". SCL-8 is regarded as an easy, valid and excellent screening tool to detect possible depression when screened in a medical context. ${ }^{[25,26]}$

Information concerning smoking cessation from admission and the next 6 weeks and information about smoking status at 1 -year follow-up was self-reported by the patients in a questionnaire. Patients' educational level was also self-reported in a questionnaire at baseline.

The interventions in relation to smoking cessation and maintenance of smoking cessation were based on the Danish recommendations for $\mathrm{CR}$ at the current time. ${ }^{[23]}$ The interventions were divided into three phases. Phase one ran from admission to discharge. In phase one the patients were informed about the risks of continuing to smoke, the health benefits of quitting and the treatment options, which were available. Treatment methods included nicotine replacement therapy and individual counselling. Phase two ran from the discharge and six-twelve weeks ahead. Phase two focused on participation in individual counselling. Phase three ran from the six-twelve weeks after discharge and beyond. In phase three the focus was on following up on whether patients still maintained their smoking cessation and to inform of smoking cessation courses for continuous smokers. The patients were followed by their GP in phase three.

In the analysis the inclusion criteria were self-reported smoking cessation at admission or in the next six weeks. Patients should also have been screened for depression six weeks after admission. In addition, patients had to specify their smoking status at 1-year follow-up. All patients gave written informed consent. Exclusion criteria were severe co morbidities, severe apoplexy, dementia, severe psychiatric disease, mental retardation, and alcohol or drug addiction. 


\section{Statistical analysis}

Data were analyzed using the statistical programme STATA12. Qui square test and logistic regression were used as statistical method to analyze data. Assumptions for the statistical method were checked prior to the analysis. Logistic regression was used to check for effect modification and to calculate an adjusted estimate controlled for the relevant confounders gender and educational level. $P$-value $<.05$ was applied as level for statistical significance.

\section{Results}

As shown in Figure 1, 388 first-incidence MI patients were admitted at Aarhus University Hospital, 333 were referred to the $\mathrm{CR}$ and 55 were excluded because they were disabled. A total of 309 patients participated in the CR, of these data were available on 295 patients. One hundred and sixty-nine patients were smokers at admission and 168 of these were screened for depression 6 weeks after admission. One hundred and five patients stopped smoking at admission or within the following 6 weeks. Data on smoking status at 1-year fol- low up were available for a total of 98 patients and these patients were used in our analyses.

A quarter of the patients (25\%) in the sample population were screened positive for depression. In men $17 \%$ were screened positive for depression and in women the amount was $43 \%$. A quarter of the patients had an educational level equal to elementary school. In patients with elementary school as the highest completed education $50 \%$ were screened positive for depression, whereas only $16 \%$ of the patients with educational level higher than elementary school were screened positive for depression. The amount of patients who were 55 years or younger, was $38 \%, 46 \%$ of the patients were not working and $21 \%$ were living alone. The socio-demographic variables among the study population concerning age, occupation and marital status did not differ significant as all $p$-values were $>.05$. There were significant difference in the socio-demographic variables among the sample population concerning gender $(p$-value $=.01)$ and educational level $(p$-value $=.001)($ see Table 1$)$.
Figure 1.

Flowchart for the population

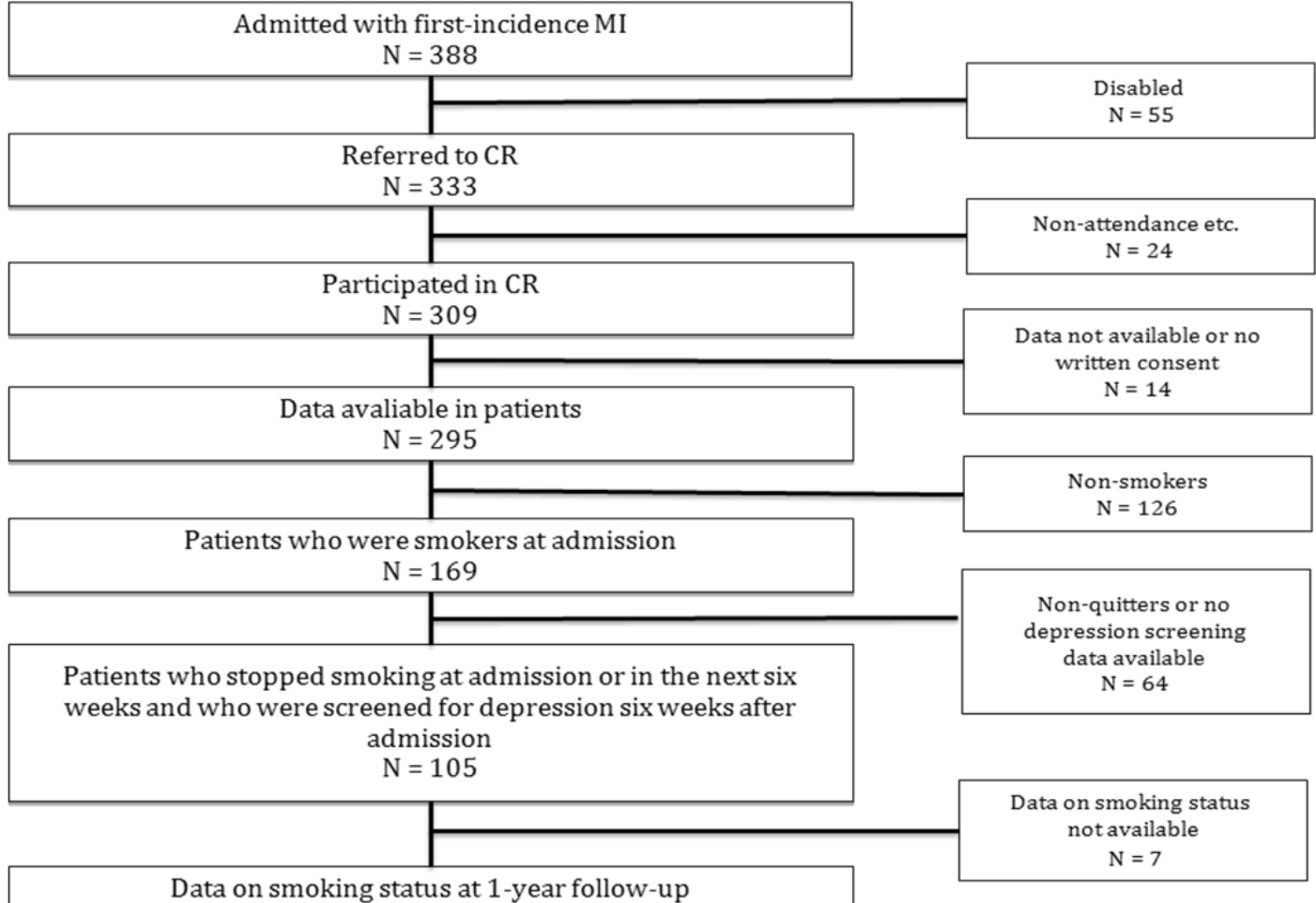
$\mathrm{N}=98$
A total of 32 patients participated in smoking rehabilitation, of these 23 were screened negative for depression, and 9 were screened positive for depression. A total of 66 patients did not participate in the part of the rehabilitation concerning smoking, of these 51 were screened negative for depression, and 15 were screened positive for depression. As shown in table 2, there was a greater likelihood of patients screened 88 positive for depression not to participate in the smoking cessation part of the CR, compared to patients screened negative for depression. A significant association was however not found (crude OR $=0.75, p$-value $=.56$ ), not even when adjusted for gender and educational level (crude OR $=0.66$, $p$-value $=.75)$. 
Table 1. Baseline socio-demographic variables among the sample population

\begin{tabular}{|c|c|c|c|c|}
\hline \multirow{2}{*}{ Characteristics } & \multicolumn{3}{|c|}{ n (\%) } & \multirow{2}{*}{$p$-value } \\
\hline & All patients $(n=98)$ & Non depression $(n=74)$ & Depression $(n=24)$ & \\
\hline Gender & & & & .01 \\
\hline - Men & $70(71)$ & $58(78)$ & $12(50)$ & \\
\hline - Women & $28(29)$ & $16(22)$ & $12(50)$ & \\
\hline Age & & & & .06 \\
\hline$\cdot \leq 55$ years & 37 (38) & $24(32)$ & $13(54)$ & \\
\hline - > 55 years & $61(62)$ & $50(68)$ & $11(46)$ & \\
\hline Educational level & & & & .001 \\
\hline - Elementary school & $24(25)$ & $12(16)$ & $12(50)$ & \\
\hline - Higher than elementary school & $74(75)$ & $62(84)$ & $12(50)$ & \\
\hline Occupation & & & & .64 \\
\hline - Not in work & $45(46)$ & $33(45)$ & $12(50)$ & \\
\hline - In work & $53(54)$ & $41(55)$ & $12(50)$ & \\
\hline Marital status & & & & .29 \\
\hline - Lives alone & $21(21)$ & $14(19)$ & $7(29)$ & \\
\hline - Lives with partner & 77 (79) & $60(81)$ & $17(71)$ & \\
\hline
\end{tabular}

Table 2. Association between depression and participation in rehabilitation concerning smoking cessation

\begin{tabular}{lllllll}
\hline & Participation Crude OR & $\mathbf{9 5 \%}$ CI & $\boldsymbol{p}$-value & Participation Adjusted OR $^{*}$ & $\mathbf{9 5 \%} \mathbf{C I}$ & $\boldsymbol{p}$-value \\
\hline Non-depression & 1 & - & - & 1 & - & - \\
Depression & 0.75 & {$[0.29 ; 1.97]$} & .56 & 0.66 & {$[0.24 ; 1.87]$} & .44 \\
\hline
\end{tabular}

"Adjusted for gender and educational level

Table 3. Association between depression and failing to maintain a smoking cessation measured at 1-year follow-up

\begin{tabular}{|c|c|c|c|c|c|c|}
\hline & \multicolumn{6}{|c|}{ Failing smoking cessation } \\
\hline & Crude OR & $95 \% \mathrm{CI}$ & $p$-value & Adjusted OR & $95 \%$ CI & $p$-value \\
\hline \multicolumn{7}{|l|}{ Men } \\
\hline - Non depression & 1 & - & - & 1 & - & - \\
\hline - Depression & 7.67 & {$[1.97 ; 29.81]$} & .03 & 7.48 & {$[1.78 ; 31.48]$} & .01 \\
\hline \multicolumn{7}{|l|}{ Women } \\
\hline - Non depression & 1 & - & - & 1 & - & - \\
\hline - Depression & 0.60 & [0.09;3.99] & .60 & 0.55 & {$[0.07 ; 4.13]$} & .56 \\
\hline
\end{tabular}

*Adjusted for educational level

A total of 20 men failed to maintain a smoking cessation, of these 12 were screened negative for depression, and 8 were screened positive for depression. A total of 50 men maintained a smoking cessation, of these 46 were screened negative for depression, and 4 were screened positive for depression. A total of 6 women failed to maintain a smoking cessation, of these 4 were screened negative for depression, and 2 were screened positive for depression. A total of 22 women maintained a smoking cessation, of these 12 were screened negative for depression, and 10 were screened positive for depression. When analyzing data concerning depression and the ability to maintain a smoking cessation, the statistical analysis showed effect modification for the variable gender. Because of this, the further analysis was conducted stratified on gender. As shown in Table 3 there was a significant association between a positive depression screening and failing to maintain a smoking cessation for men at 1 -year follow-up (crude OR $=7.67, p$-value $=.03$ ). When adjusted for educational level a significant association was still seen (adjusted OR $=7.48, p$-value $=.01$ ). There was a greater likelihood of women screened positive for depression to maintain a smoking cessation, compared to women screened negative for depression. A significant association was however not found (crude OR $=0.60, p$-value $=.60$ ), not even when adjusted for educational level (crude $\mathrm{OR}=0.55$, $p$-value $=.56)$. 


\section{Discussion}

\subsection{Main findings}

Our study describes the association between depression and the ability to maintain a smoking cessation at a 1-year followup in patients $<75$ years old admitted at Aarhus University Hospital in Denmark with newly diagnosed first-incidence MI from the $1^{\text {st }}$ of September 2002 to the $31^{\text {st }}$ of December 2004. The number of first-incidence MI patients who were admitted in the timeframe was 388, and of these 333 patients were referred to CR. The amount of patients who participated in CR was 309, and data were available on 295 patients. Of these 169 patients were smokers at admission and 168 patients were screened for depression 6 weeks after admission. A total of 105 patients stopped smoking at admission or in the next six weeks, and data on smoking cessation at 1 -year follow-up were available in 98 patients. There was no significant difference between patients screened positive and patients screened negative for depression and their participation in CR concerning smoking cessation. There was a significant association between a positive depression screening and failing to maintain a smoking cessation in men at 1-year follow-up.

\subsection{Strengths and limitations of the study}

One of the major strengths of our study is the high response rate at the 1-year follow-up. Of 105 patients 98 patients (93\%) reported their smoking status 1 year after they were admitted with first-incidence MI. Another major strength is the fact that we managed to get all patients to participate equally in the $\mathrm{CR}$ concerning smoking cessation regardless of whether they were screened positive or negative for depression. Furthermore we reduced the risk of information bias by using a valid tool when screening the patients for depression. Due to the fact that our study was not a randomized, controlled trial, we reduced the risk of confounding by using logistic regression as the statistical method to analyze data.

One of the limitations of our study is that we have no information on whether the patients screened positive for depression in fact had consulted their GP for diagnosis or whether they actually received treatment during the first year after admission. A nurse performed the individual smoking cessation courses. However the nurse also had to talk to the patients about life with a chronic disease and other things in general concerning the patients' ability to cope with everyday life. If patients screened positive for depression had many other issues which first had to be taken care of, it is possible that there was not much time left to talk about maintaining the smoking cessation. Information about educational level and smoking cessation is self-reported by the patients in a ques- tionnaire and a risk of information bias cannot be ruled out. Patients older than 75 years were excluded from the study. Thus the results cannot necessarily be generalized to an older patient population. The results showed that there were no significant associations between a positive depression screening and the ability to maintain a smoking cessation in women. It should be mentioned that another limitation in our study is that the study population consisted of only 28 women (29\%) and the low number may have affected the ability to identify a statistically significant association.

\subsection{Comparison with existing literature}

A Swedish study published in 2007 examined the effect of different types of CR with a focus on depression. ${ }^{[2]}$ A number of 224 patients diagnosed with coronary artery disease were followed for 1 year. After a year 17 patients had died or dropped out and the follow-up rate was therefore $92 \%$. In our study the participation rate at 1-year follow-up was similar with 93\%. A Danish study published in 2011 identified, among other things, the participation in CR among 908 first-incidence MI-patients. ${ }^{[8]}$ Only $58.5 \%$ of these patients reported having participated in some kind of CR. Depression, anxiety or both had appeared in $29.2 \%$ of the patients, which is fairly the same amount as in our study population where $25 \%$ were screened positive for depression.

A lot of studies focus on smoking cessation in patients with heart disease. But is has not been possible to identify any studies with focus on the maintenance of smoking cessation in MI-patients nor in MI-patients with depression. However, an American study published in 2014 have examined smoking cessation and smoking relapse in a community based cohort of young adults followed in 25 years. ${ }^{[20]}$ The results of the study showed that relapse to smoking after a successful smoking cessation was common especially in participants with a lower educational level.

\subsection{Implications for clinical practice and future re- search}

It is very likely that our results may not only concern maintenance of smoking cessation but also could be applied to maintenance of other types of health behaviour such as eating and exercise habits or alcohol intake. Depression has a significant impact on patients' ability to maintain a smoking cessation. It is therefore of great importance that patients are screened for depression so that they can be identified and helped the best possible way. Several studies support a systematic screening for depressive disorders. ${ }^{[8,12,13,15]}$ Our results show that in spite of the fact that patients screened positive and negative for depression participated fairly equal in CR concerning smoking cessation, patients screened posi- 
tive for the depression maintained a smoking cessation to a lesser extent. Future research should focus on how we help depressed patients the best possible way when it apparently is not enough just to participate in CR.

\section{Conclusions}

There was no significant difference between patients screened positive and patients screened negative for depression and their participation in CR concerning smoking cessation. There was a significant association between a positive depression screening and failing to maintain a smoking cessation in men at 1-year follow-up. No significant associations were found in women. The results were consistent regardless of adjusting for gender and educational level or not.

\section{Funding}

The study was supported by the Ministry of the Interior and Health, the Ministry of Social Affairs in Denmark (grant number 2003-14004-4), the Danish Heart Foundation (grant number 04-10-B99-A150-22175), and the Aarhus University Hospital Research Initiative.

\section{ACKNOWLEDGeMENTS}

The authors give a special thank you to Aarhus Rehabgroup: Birgitte Gustafson, Dorrit G Andersen, Karen Lind (Department of Cardiology, Aarhus University Hospital) Mads Melgaard Madsen (Department of Social Medicine and Psychiatry, Municipality of Aarhus), Jørgen Lous and Bo Christensen (Department of General Practice, University of Aarhus), Elisabeth Egeskov (Counselling Centre of the Danish Heart Foundation in Aarhus), and Kirsten VintherJensen (Health Promotion and Prevention, Centre of Public Health, Central Denmark Region).

\section{CONFLicts OF INTEREST Disclosure}

The authors declare that they have no competing interests.

\section{REFERENCES}

[1] Heran BS, Chen JMH, Ebrahim S, et al. Exercise-based cardiac rehabilitation for coronary heart disease (review). Cochrane Database Syst Rev. 2011; 6(7): 1-94. http://dx.doi.org/10.1002/146 51858.cd001800.pub2

[2] Karlsson MR, Plüss CE, Held C, et al. Effects of expanded cardiac rehabilitation on psychosocial status in coronary artery disease with focus on type D characteristics. J Behav Med. 2007; 30(3): 25361. PMid: 17417723 . http://dx.doi.org/10.1007/s10865-0 07-9096-5

[3] Chatziefstratiou AA, Giakoumidakis K, Brokalaki H. Cardiac rehabilitation outcomes: Modifiable risk factors. Br J Nurs. 2013; 22(4): 200-7. PMid: 23448981. http://dx.doi.org/10.12968/bjon .2013 .22 .4 .200

[4] Plüss CE, Billing E, Held C, et al. Long-term effects of an expanded cardiac rehabilitation programme after myocardial infarction or coronary artery bypass surgery: a five-year follow-up of a randomized controlled study. Clin Rehabil. 2011; 25(1): 79-83. PMid: 20702510. http://dx.doi.org/10.1177/0269215510376006

[5] Goel K, Lennon RJ, Tilbury RT, et al. Impact of cardiac rehabilitation on mortality and cardiovascular events after percutaneous coronary intervention in the community. Circulation. 2011; 123(21): 2344-52. PMid: 21576654. http://dx.doi.org/10.1161/CIRCULATION AHA . 110.983536

[6] Giallauria F, Lucci R, D'Agostino M, et al. Two-year multicomprehensive secondary prevention program: favorable effects on cardiovascular functional capacity and coronary risk profile after acute myocardial infarction. J Cardiovasc Med. 2009; 10(10): 772-80. PMid: 19531961. http://dx.doi.org/10.2459/JCM.0b013e3 2832d55fe

[7] Giannuzzi P, Temporelli PL, Marchioli R, et al. Global secondary prevention strategies to limit event recurrence after myocardial infarction. Arch intern med. 2008; 168(20): 2194-204. PMid: 19001195. http://dx.doi.org/10.1001/archinte.168.20.2194

[8] Larsen KK, Vestergaard M, Søndergaard J, et al. Rehabilitation status three month after first-time myocardial infarction. Scand J
Prim Health Care. 2011; 29: 210-15. PMid: 22126219. http: //dx.doi.org/10.3109/02813432.2011.629147

[9] Rea TD, Heckbeck SR, Kaplan RC. Smoking status and risk for recurrent coronary events after myocardial infarction. Ann Intern Med. 2002; 137(6): 494-500. PMid: 12230350. http://dx.doi.org/1 0.7326/0003-4819-137-6-200209170-00009

[10] Hasdai D, Garratt KN, Grill DE, et al. Effect of smoking status on the long-term outcome after successful percutaneous coronary revascularization. N Engl J Med. 1997; 336(11): 755-61. PMid: 9052653. http://dx.doi.org/10.1056/NEJM199703133361103

[11] Nielsen TJ, Vestergaard M, Christensen B, et al. Mental health status and risk of new cardiovascular events or death in patients with myocardial infarction: A population-based cohort study. BMJ Open. 2013; 3(8): 1-10. PMid: 23913773. http://dx.doi.org/10.11 36/bmjopen-2013-003045

[12] Kronish IM, Reickmann N, Halm EA, et al. Persistent depression affects adherence to secondary prevention behaviors after acute coronary syndromes. J Gen Intern Med. 2006; 21: 1178-83. PMid: 16899061. http://dx.doi.org/10.1111/j.1525-1497.2006 $.00586 . \mathrm{x}$

[13] Doyle F, Rohde D, Rutkowska A, et al. Systematic review and meta-analysis of the impact of depression on subsequent smoking cessation in patients with coronary heart disease: 1990 to 2013. Psychosom Med. 2014; 76(1): 44-57. PMid: 24367125. http://dx.doi.org/10.1097/PSY.0000000000000020

[14] Olsen LR, Jørgensen PM, Bech P. The prevalence of depression in Denmark. Ugeskr Laeger. 2007; 169(16): 1425-26. PMid: 17484835.

[15] Smolderen KG, Spertus JA, Reid KJ, et al. The association of cognitive and somatic depressive symptoms with depression recognition and outcomes after myocardial infarction. Circ Cardiovasc Qual Outcomes. 2009; 2: 328-37. PMid: 20031858. http://dx.doi .org/1 0.1161 /CIRCOUTCOMES.109.868588

[16] Pedersen SS, Middel B, Larsen ML. Posttraumatic stress disorder in first-time myocardial infarction patients. Heart Lung. 2003; 
32(5): 300-7. http://dx.doi.org/10.1016/S0147-9563(03 ) 00097-9

[17] Nielsen KM, Faergeman O, Foldsprang A, et al. Cardiac rehabilitation: Health characteristics and socio-economic status among those who do not attend. Eur J Public Health. 2008; 18(5): 479-83. PMid: 18614608. http://dx.doi.org/10.1093/eurpub/ckn060

[18] Alter DA, Iron K, Austin PC, et al. Socioeconomic status, service patterns, and perceptions of care amoing survivors of acute myocardial infarction in Canada. JAMA. 2004; 291(9): 1100-7. PMid: 14996779. http://dx.doi.org/10.1001/jama.291.9.1100

[19] Marti J. Successful smoking cessation and duration of abstinence an analysis of socioeconomic determinants. Int J Environ Res Public Health. 2010; 7(7): 2789-99. PMid: 20717538. http://dx.doi.o rg/10.3390/ijerph7072789

[20] Caraballo RS, Kruger J, Asman K, et al. Relapse among cigarette smokers: The CARDIA longitudinal study - 1985-2011. Addict Behav. 2014; 39(1): 101-6. PMid: 24172753. http://dx.doi.org/1 $0.1016 / \mathrm{j}$. addbeh.2013.08.030

[21] Gee ME, Bienek A, Campbell NRC, et al. Prevalence of and barriers to preventive lifestyle behaviors in hypertension (from a national survey of Canadians with hypertension). Am J Cardiol. 2012; 109(4):
570-5. PMid: 22154320. http://dx.doi.org/10.1016/j.amj card.2011.09.051

[22] Meillier LK, Nielsen KM, Larsen ML, et al. Socially differentiated cardiac rehabilitation: Can we improve referral, attendance and adherence among patients with first myocardial infarction? Scand J Public Health. 2012; 40: 286-93. PMid: 22637368. http: //dx.doi.org/10.1177/1403494812443600

[23] Network of health promoting hospitals in Denmark, Danish society of cardiology, the Danish heart foundation. Heart rehabilitation on Danish hospitals. 2004 Apr. Report No.: ISBN87-988376-5-6. 60 p.

[24] Christensen KS, Fink P, Toft T, et al. A brief case-finding questionnaire for common mental disorders: the CMDQ. Fam Pract. 2005; 22(4): 448-57. PMid: 15814580. http://dx.doi.org/10.1093 /fampra/cmi025

[25] Fink P, Ørnbøl E, Huyse FJ, et al. A brief diagnostic screening instrument for mental disturbances in general medical wards. J Psychosom Res. 2004; 57(1): 17-24. http://dx.doi.org/10.1016/S0022 -3999 (03) 00374-X

[26] Fink P, Ørnbøl E, Hansen MS, et al. Detecting mental disorders in general hospitals by the SCL-8 scale. J Psychosom Res. 2004; 56(3): 371 5. http://dx.doi.org/10.1016/S0022-3999(03)00071-0 